\title{
El Campo de Gibraltar, cara y cruz de un paisaje de frontera
}

Silvia Fernández Cacho, Centro de Documentación y Estudios del IAPH
"El paisaje detrás de Algeciras es fértil y agradable; las montañas empiezan a la distancia de una legua; los bosques de alcornoques que las cubren dan leña a sus habitantes; su vista, preciosa, y la blancura de Algeciras a sus pies reflejada en el mar durante los dias de calma, forman un conjunto grandioso".

Viaje de Gibraltar a Málaga

Francis Carter (1771-72)

El Campo de Gibraltar ${ }^{2}$ imprime en los sentidos de quienes lo recorren sensaciones contradictorias. A la rotunda belleza de su configuración geográfica se contrapone el uso intensivo de una bahía, la de Algeciras, que ha sido devorada por las necesidades de la industria, el comercio y la residencia en el último medio siglo de su historia.

El paisaje campogibraltareño no deja indiferente a quienes lo observan. Sus rasgos más definitorios no se muestran en detalles sólo perceptibles para el ojo experto sino que parecen competir para dominar su imagen, reflejando la cara y la cruz del uso y aprovechamiento del territorio por parte de los seres humanos. Asi, junto a la exuberancia de la geomorfología, la diversidad biológica y el aprovechamiento sostenible de los recursos del parque natural de los Alcornocales, se muestra sin tapujos, a modo de exhibición, un muestrario de las formas de intervención antrópica más agresivas.

Estos contrastes se evidencian también en los modelos de crecimiento de los núcleos urbanos de la zona. Algeciras con sus más de 115.000 habitantes $^{3}$ ha sacrificado los potenciales beneficios de su privilegiado emplazamiento y de su pasado histórico en pos de un crecimiento desordenado que ha supuesto la pérdida paulatina de su patrimonio natural, cultural y paisajístico. El resto de cabeceras municipales muestran situaciones diversas, desde la copia del modelo algecireño a menor escala que caracteriza el paisaje urbano de la Línea de la Concepción, a las situaciones intermedias de Los Barrios, con una importante expansión de su suelo urbano e industrial (aglutina en su término municipal el 75\% del suelo industrial de la comarca) o San Roque, que mantiene el interés de su centro histórico (declarado conjunto histórico en 1975) a pesar del impacto que también la industria pesada produce en su término municipal. El extremo opuesto se encuentra representado por el encanto del pueblo viejo de Castellar de la Frontera o Castellar "Viejo". Castellar Viejo ha sido parcialmente recuperado durante las tres últimas décadas después del traslado de su población a Castellar "Nuevo" en los años 70 del siglo XX, aunque dicha recuperación se asocia mayoritariamente a usos turísticos y no residenciales.

Secularmente mal comunicada, la mejora de sus principales arterias de comunicación ha sido muy importante en los últimos 20 años. Si el acceso al Campo de Gibraltar se realiza desde Málaga, rápidamente se percibe a la izquierda de la carretera la presencia imponente de un polígono petroquímico donde conviven una refinería de petróleo, una fábrica de acero inoxidable, una central térmica de carbón y otras empresas que completan la imagen de una zona de gran potencia industrial que abraza hasta la asfixia a uno de los sitios arqueológicos más importantes de Andalucía, Carteia, primera colonia latina fuera de la península italiana.

La contaminación que estas empresas producen, reiteradamente denunciada por grupos ecologistas y colectivos ciudadanos ${ }^{4}$, no se ha visto compensada con una promoción del empleo ni con el aumento de los niveles de renta de sus habitantes. Todo lo contrario, el Campo de Gibraltar destaca por ocupar siempre los primeros lugares en las tasas de paro a nivel nacional, afectando ya a mediados de 2010 a un 40\% de los jóvenes menores de 35 años ${ }^{5}$. A pesar de estos datos, una y otra vez se recurre al argumento de la creación de empleo para promover la continua ampliación de los poligonos industriales.

Desde el sur el acceso es más accidentado y un cordón de sierras llega hasta el mar de forma abrupta, dibujando un perfil de acantilados al que se han superpuesto las hileras de aerogeneradores para aprovechar la energía eólica. A pesar del impacto visual que producen y del daño que provocan a las aves que cruzan el estrecho 
cada año, puede pensarse que su instalación ha sido prácticamente inevitable. En una época de expansión de las plantas de generación de energías renovables, esta zona fue una de las primeras en ensayar las posibilidades de una tecnología de producción energética que convierte en recurso económico una de las principales características de su meteorología, el viento.

Por la carretera que recorre por la costa el parque natural del Estrecho desde Tarifa a Algeciras se disfrutan las mejores vistas de la orilla opuesta, divisándose Tánger y Ceuta sin dificultad en los dias en los que el viento sopla desde el poniente. La entrada en Algeciras por esta carretera ofrece en primer término la visión de su puerto, uno de los más importantes de Europa en tráfico de mercancias. La expansión paulatina de las instalaciones portuarias han profundizado las heridas de un paisaje castigado, el de la bahía de Algeciras, que se pierde tras grúas y contenedores, y el de su antaño paseo marítimo que ha sido borrado de su geografía al ganar el puerto terreno al mar en la fachada de la ciudad que conectaba con su orilla. Cuando esta orilla muere en una playa (el Rinconcillo, Palmones, Getares...), los dias que sopla el levante el mar deposita periódicamente en la arena los residuos vertidos desde los barcos que pasan, y descansan, en sus aguas.

Desde Jerez de la Frontera, por la ruta del Toro, se accede a la bahía algecireña por Los Barrios atravesando el parque natural de los Alcornocales. El desdoble de la antigua carretera comarcal en autovía por esta ruta ha creado no pocos conflictos ecológicos pero ha mejorado enormemente el sistema de comunicaciones terrestre de la provincia de Cádiz. Desde este acceso, tras un repecho de la carretera, se muestra una de las mejores vistas del peñón de Gibraltar.

Es efectivamente el peñón el que conserva el protagonismo en la bahía. Hito geográfico convertido en referente cultural, forma parte de un imaginario colectivo arraigado en un pasado mítico que lo convirtió en una de las columnas erigidas por Hércules, y que mira a su gemela, al otro lado del Estrecho, el monte Hacho en Ceuta. Simbolizando el fin del mundo (non plus ultra), las columnas de Hércules se representan en los escudos de España, Andalucia, Melilla, Cádiz, etc.

Desde la firma del tratado de Utrecht en 1713 por el que España entrega a Gran Bretaña el peñón, una nueva frontera marca el paisaje campogibraltareño y la idiosincrasia de sus habitantes. Asociado durante décadas con la evasión fiscal y el contrabando de tabaco, hoy en dia Gibraltar se ha convertido también en referente para la investigación científica sobre los neandertales, que tuvieron en la cueva Gorham uno de sus últimos refugios en el continente europeo.

El cierre de la verja que separaba Gibraltar de la Línea de la Concepción y el empeño del régimen franquista por situar cerca de la roca la refinería de petróleo acabaron por desencadenar el proceso depredador de sus valores culturales y naturales. No sólo fue dañada Carteia en el proceso de construcción de la refineria, sino también el cerro del Prado, asentamiento fenicio descubierto a principios de los años 1970 a dos kilómetros de aquella. No son estos los únicos sitios arqueológicos que se han visto afectados por las intervenciones en el territorio, pero en esos momentos el estado incipiente de la gestión del patrimonio histórico en general y el desconocimiento del arqueológico en particular tampoco ayudaron a su salvaguarda.

Frontera entre naciones, pero también entre continentes, el Campo de Gibraltar está separado del continente africano por un estrecho de poco más de 14 kilómetros en su punto más próximo. Al otro lado se vislumbra el territorio que hoy forma parte del reino de Marruecos, con el que han compartido siglos de historia a través de ese estrecho que ha sido en el pasado, y sigue siendo en el presente, puente de unión y límite fronterizo.

El comercio, la subsistencia y/o la expansión colonial han incitado a muchas poblaciones a cruzar este peligroso estrecho ya sea de norte a sur (y viceversa), entre Europa y África, como desde el oriente mediterráneo hacia tierras atlánticas. De la antigüedad de estos últimos contactos ha quedado constancia gráfica en la Cueva de la Laja en Jimena de la Frontera (inicios del 1. er milenio a.n.e.) en la que se muestran representadas en detalle las embarcaciones que arribaban a la costa.

El intenso tráfico de navíos de diverso calado y su situación estratégica también ha sembrado el paisaje subacuático de numerosos hallazgos arqueológicos mientras en tierra firme se erigen torres de vigilancia costera medievales y modernas, búnkeres y fuertes costeros contemporáneos y núcleos de población defendidos por recias fortificaciones. Entre estas últimas destaca, una vez más, por el mantenimiento de su impronta en el paisaje, la de Castellar de la Frontera aunque hay que reseñar, por la espectacularidad del hallazgo, los restos de la muralla medieval de Algeciras, en pleno corazón de la ciudad, para los que se van concretando soluciones de integración en un entorno poco amable pero con un excelente potencial divulgativo.

El mar también ha sido la fuente principal de recursos en el Campo de Gibraltar desde el Paleolítico hasta que el avance de la industria petroquímica y del papel fueron ocupando el espacio de la pesca y la transformación de sus productos. La explotación de los recursos pesqueros, su transformación, la producción de envases para su transporte y su comercialización propiciaron su primera gran expansión demográfica y económica en época romana. De esta época se han conservado interesantes referencias literarias y vestigios arqueológicos que así lo atestiguan (factorías de salazón en Carteia, la Villa Vieja de Algeciras o Getares también en Algeciras, alfares de la Venta del Carmen en Los Barrios o el Rinconcillo en Algeciras, etc.).

A pesar de la pérdida de muchos de sus valores culturales y naturales, el Campo de Gibraltar atesora todavía un importante po- 


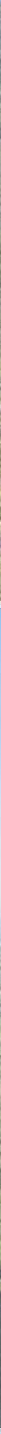




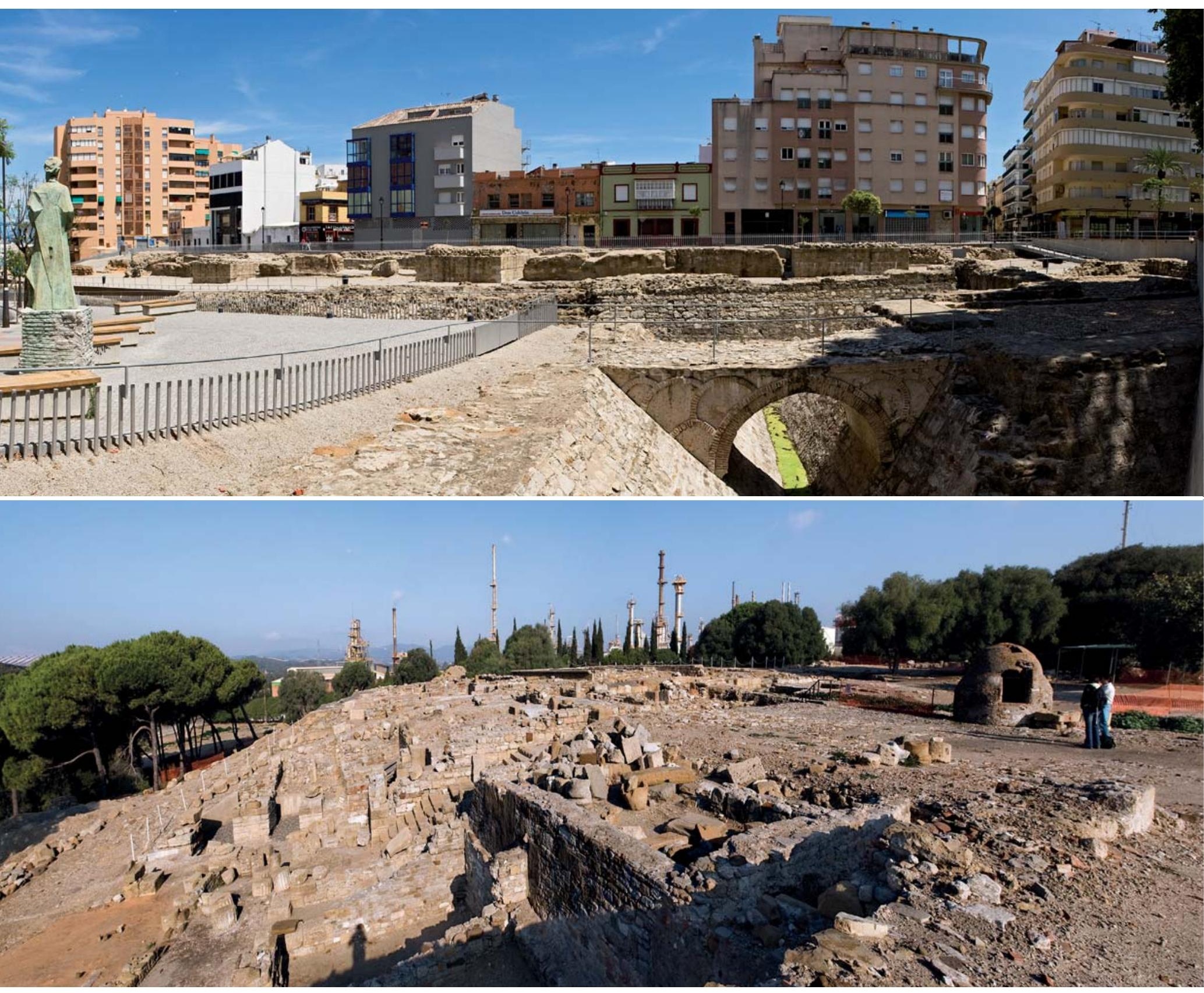

Murallas medievales de Algeciras

Ruinas de Carteia e instalaciones industriales al fondo

tencial patrimonial. Su Plan de Ordenación del Territorio propone medidas tanto para la preservación como para el uso y disfrute de aquellos recursos con más posibilidades de valorización y/o proyección paisajistica ${ }^{6}$, integrando los relacionados con la arquitectura defensiva, los abrigos y cuevas con representaciones rupestres, entre las que destacan las del tajo de Bacinete (Los Barrios), y otros lugares singulares (Carteia en San Roque, acueducto del Cobre en Algeciras, faro de Punta Carnero en Algeciras, etc.).

Junto a ellos conviven otros lugares de extraordinario interés y casi desconocidos o poco estudiados, como Montelatorre o Barbésula, y un patrimonio inmueble en ámbitos urbanos que en ciudades como Algeciras apenas ha sobrevivido más allá de la ensoñación literaria que producen los textos de los viajeros que un día valoraron su hermosura.

\section{Notas}

${ }^{1}$ Cita extraída de BUENO LOZANO, M. (1988) El Renacer de Algeciras (a través de Ios viajeros). Algeciras: Alba Editorial, 1988, p. 66.

${ }^{2}$ En esta sección los municipios de Tarifa y Jimena de la Frontera, que forman parte de la comarca administrativa del Campo de Gibraltar, van a considerarse, por sus características paisajisticas, fuera de su delimitación, quedando integrados con otros municipios: en el paisaje del litoral atlántico del Estrecho, el primero, y en el de la sierra de Cádiz-serranía de Ronda, el segundo.

${ }^{3}$ Datos extraídos del Sistema de Información Multiterritorial de Andalucia para 2010. ${ }^{4}$ Véase el informe de Greenpeace Crisis ambiental y de salud en la bahía de Algeciras/Bahia de Gibraltar de junio de 2009 en www.greenpeace.org/raw/content/ espana/reports/090619.pdf [consulta: 20/07/2011], o el reportaje de televisión española Algo huele mal del programa Report, emitido en $2010<$ http://www.rtve. es/alacarta/videos/repor/repor-algo-huele-mal/774421/> [consulta: 12/10/2011]. ${ }^{5}$ Datos de un informe del sindicato Comisiones Obreras publicados en www.campo degibraltar.es

${ }^{6}$ En www.juntadeandalucia.es/obraspublicasyvivienda/obraspublicasyvivienda/portalweb/web/areas/ordenacion/texto/0ed37ccb-2216-11df-8891-555105b916a8 